\title{
Interdisciplinaridade no contexto da Ciência da Informação: correntes e questionamentos
}

\author{
João Arlindo dos Santos Neto \\ Doutorando; Universidade Estadual Paulista "Júlio de Mesquita Filho", Marília, SP, Brasil \\ santosneto@uel.br \\ Juliana Cardoso dos Santos \\ Doutoranda; Universidade Estadual Paulista "Júlio de Mesquita Filho", Marília, SP, Brasil \\ julimath21@gmail.com \\ Paulo Sérgio Teles \\ Mestrando; Universidade Estadual Paulista "Júlio de Mesquita Filho", Marília, SP, Brasil \\ pauloci2014@gmail.com \\ Marta Lígia Pomim Valentim \\ Doutora; Universidade Estadual Paulista "Júlio de Mesquita Filho", Marília, SP, Brasil \\ valentim@valentim.pro.br
}

\begin{abstract}
Resumo: O artigo investiga a interdisciplinaridade no contexto da Ciência da Informação (CI), seus conceitos e particularidades a partir de revisão de literatura. Objetiva elucidar a discussão a respeito da temática e das abordagens que têm sido empregadas nos estudos e, também, propor um conceito embrionário para a interdisciplinaridade. Analisa os primeiros estudos realizados por Lena Vania Pinheiro e os confronta com as investigações mais recentes. Conclui que a CI, a Biblioteconomia e a Ciência da Computação exercem um diálogo interdisciplinar, isto é, essas áreas interagem e criam conhecimento ou aperfeiçoam o já existente, sendo útil e reconhecido pelas três áreas envolvidas.
\end{abstract}

Palavras-chave: Interdisciplinaridade. Ciência da Informação. Teoria da Complexidade.

\section{Introdução}

A interdisciplinaridade pode ser considerada uma ação integradora de saberes, pois pressupõe a troca e a cooperação entre distintas áreas de conhecimento. $\mathrm{O}$ movimento interdisciplinar requer negociações, esforços e desconstruções, por isso mesmo não é linear, visto que é na interdisciplinaridade que o pesquisador reconhece ou deveria reconhecer a fragmentação da Ciência.

Nesse sentido, buscou-se evidenciar que, para a interdisciplinaridade ocorrer de fato, é necessário perceber, reconhecer e comunicar as fragilidades do 
campo científico, pois é preciso que haja, mutuamente, o aprofundamento e a construção de conhecimento 'novo' ou incremental.

Com base nas leituras realizadas, é possível inferir que do caos surge a ordem ou a auto-organização, já que o conhecimento constrói-se entre a ordem e a desordem e pressupõe troca e diálogo para avançar. O objetivo deste trabalho é refletir a respeito da temática e das abordagens que têm sido empregadas nos estudos e, também, propor um conceito embrionário para a interdisciplinaridade. Nessa perspectiva, analisaram-se os primeiros estudos realizados por Lena Vania Pinheiro sobre o tema, confrontando-os com as investigações mais recentes.

Como procedimento metodológico, realizou-se uma revisão bibliográfica com o intuito de identificar o panorama da interdisciplinaridade no âmbito da Ciência da Informação (CI) e de áreas correlatas. A argumentação alicerça-se na interação entre diferentes discursos e é apresentada nas seguintes seções: Ciência, em que se discute brevemente o seu significado e sua característica como ciência moderna ou pós-moderna, relaciona-se a Teoria Geral dos Sistemas à Teoria da Complexidade e, traça um comparativo entre a especialização e a hiperespecialização; Interdisciplinaridade, em que apresentam-se conceitos e questionamentos de como essa prática pode ser realizada, bem como a proposta de um conceito embrionário para a interdisciplinaridade; Características da CI, onde procurou-se discutir os aspectos marcantes da CI e a qual tipo de ciência ela tem sido classificada; e Interdisciplinaridade no âmbito da CI, em que se analisa os estudos realizados na CI, que se preocuparam em analisar a existência da prática interdisciplinar.

\section{Ciência}

Compreender todos os elementos que compõem o que se denomina de Ciência vem sendo objeto de estudo de muitos pesquisadores de diferentes áreas do conhecimento, entretanto, ainda não se chegou a um consenso hegemônico, devido à multiplicidade de significados sobre o que seja Ciência. Contudo, foi 
da necessidade de comprovação de fatos, explicados a partir do senso comum, que surgiu o conhecimento científico (LENZI; BRAMBILLA, 2006).

Da mesma maneira que é difícil definir Ciência, é igualmente difícil definir o que é conhecimento científico. Desse modo, como norte desse trabalho, corrobora-se a ideia de Santana (2012, p. 4), ao afirmar que, mesmo com o grande número de percepções em relação à Ciência, ela:

[...] constitui-se de membros regidos por leis, teorias, metodologias, há a concordância de que ela se destina prioritariamente à amplitude e renovação do conhecimento sobre o homem e a natureza.

A Ciência e o conhecimento científico, em linhas gerais, apresentam características similares como, por exemplo: objetividade, confiabilidade e verificabilidade, cujos resultados obtidos advêm de métodos racionais, específicos e sistematizados. Para Chalmers (1993, p. 19), “[...] a ciência é baseada no que podemos ver, ouvir, tocar, etc." e não permite especulações e suposições.

Ao refletir sobre a interdisciplinaridade, acredita-se que seja fundamental aprofundar os construtos teóricos que definem Ciência Moderna e Ciência PósModerna, Teoria Geral dos Sistemas (TGS), Teoria da Complexidade (TC), especialização e hiperespecialização. Defende-se a importância em compreender os aspectos que permeiam essas temáticas, visto que foram norteadores para o surgimento do conceito de interdisciplinaridade.

\subsection{Ciência Moderna e Pós-Moderna}

A Ciência Moderna surge no contexto da Revolução Científica, entre os séculos XVI e XVII, “[...] período da história europeia em que, [...] os fundamentos conceituais, metodológicos e institucionais da ciência moderna foram assentados pela primeira vez.” (HENRY, 1998, p. 13), a partir dos descobrimentos de Copérnico (século XVI) e Galileu, Bacon e Newton (Século XVII). A Revolução Científica vigorou, fundamentalmente, sob o domínio das Ciências Naturais e, para os autores supracitados, a meta da Ciência Moderna 
relacionava-se ao melhoramento da vida do homem na Terra (CHALMERS, 1993).

No Século XVII, a religião desvincula-se do Estado, e a fonte de conhecimento passa a ser a razão e a experiência. Sendo assim, o empirismo baseado nos princípios iluministas, em que a racionalidade científica e a técnica passam a exercer supremacia na cultura ocidental, tornou-se condição fundamental.

Segundo Harvey (2000), a Ciência Moderna baseava-se no modelo de decomposição dos objetos em partes, ou seja, trabalhava com especificidades. Tal fator favorecia a organização do conhecimento, mas revelava características fragmentadoras que se desvinculavam das abstrações e complexidades que fazem parte da vida cotidiana. Assim, a Ciência Moderna foi fundamentando-se no conhecimento voltado à especialização e à disciplinarização, baseada no rigor científico que, por sua vez, tornou-a refém das rígidas fronteiras que ela mesma produziu, impedindo avanços inerentes à complexidade do mundo real, que exige um olhar subjetivo, plural e flexível (HARVEY, 2000).

No Século XX, a complexidade do mundo real e as novas configurações sociais são evidentes, e essas mudanças trouxeram problemas ao modelo de Ciência em vigor que não pressupunha interações. As fronteiras e compartimentalizações, originadas no modelo cartesiano, são questionadas sob uma nova ótica, isto é, a da complexidade, que apresenta novas indagações de diferentes áreas do conhecimento científico (ARAÚJO et al., 2007).

É nesse cenário de crise do modelo científico, até então em vigor, que se desenvolve a perspectiva pós-moderna. Conceito controverso e bastante criticado, mas que passou a ser amplamente utilizado nas pesquisas, a fim de representar tanto o novo arranjo social, quanto o embate científico ocasionado pela crise na Ciência Moderna.

A Ciência Pós-Moderna surge com o intuito de solucionar problemas não existentes como, por exemplo, o aumento exponencial de informação. Essa Ciência enfoca o sujeito reflexivo, que necessita ser pensado em todas as suas possibilidades. A ideia da pós-modernidade corresponde à fase pós-industrial da sociedade, sendo modificada de acordo com as tecnologias digitais de 
informação que surgem com o aparecimento da sociedade de consumo e dos mass media, dos sistemas organizados de produção, difusão e recepção da informação e que são geridos por empresas especializadas na comunicação de massa (LEMOS, 2002).

Lyotard (2004) foi contundente ao afirmar a existência do pósmodernismo, que surge na segunda metade do século XX. Uma das características mais fortes do pós-modernismo, defendida por Baudrillard (1991), refere-se ao estágio de desenvolvimento social e econômico da sociedade contemporânea que chegou a um nível em que não se consegue:

[...] separar o contexto econômico ou produtivo do processo ideológico ou cultural. Artefatos culturais, imagens, representações, até sentimentos e estruturas psíquicas, tornaram-se parte do mundo econômico. (BAUDRILLARD, 1991, p. 56).

Para Castells (1999), o paradigma pós-moderno caracteriza-se por: a) a informação é sua matéria-prima, e todas as tecnologias agem sobre ela; b) a informação é parte integral de toda atividade humana, e os efeitos das tecnologias são inerentes a todos os processos de vida individual e coletiva; c) todos os sistemas ou o conjunto de relações funcionam de acordo com a lógica de redes; d) o paradigma é baseado na flexibilidade de processos, organizações e instituições, que podem ser modificados em níveis diferenciados; e) a existência da crescente convergência de tecnologias específicas para um sistema altamente integrado, em que um elemento não pode ser imaginado sem o outro.

A Ciência Pós-Moderna exige percepções múltiplas, porém, ressalta-se que ela não refuta o valor da Ciência Moderna, ao contrário, reconhece o desenvolvimento possibilitado por essa, que proporcionou avanços alicerçados no rigor e na pragmática. A Ciência Pós-Moderna evidencia a importância de refletir sobre a completude das coisas, pois ela não se baseia só nas interrelações para a construção de um campo científico, mas também tem como prioridade colocar o homem no centro, sendo, portanto, interdisciplinar a sua construção.

Santos (2003) afirma que a principal diferença entre a Ciência Moderna e a Ciência Pós-Moderna está no fato de essa última considerar o senso comum 
enriquecedor. Para esse autor, a Ciência Moderna opôs-se ao senso comum, considerando-o superficial, ilusório e falso. Inversamente, a Ciência PósModerna, procura ir ao encontro desse tipo de conhecimento, a fim de enriquecer a relação das pessoas com os fenômenos do mundo.

A pós-modernidade critica a crescente superficialidade e o imediatismo das relações sociais, critica o indivíduo 'asocial' e a subjugação sem percepção. A proposta do pós-modernismo visa produzir a polifonia, ou seja, o importante não está no local de partida, mas sim no caminho percorrido.

A CI é um dos campos de conhecimento que nasce nesse novo contexto das ciências pós-modernas, mas essa discussão será apresentada mais adiante no texto. Na sequência, apresentam-se algumas características da TGS e TC.

\subsection{Teoria Geral dos Sistemas (TGS) e Teoria da Complexidade (TC)}

A TGS surge na Biologia, concebida na década de 50, pelo pesquisador Ludwig von Bertalanffy, visando melhorar a compreensão dos sistemas por meio de um enfoque sistêmico. Ela apresenta muito mais do que similaridades superficiais, visto que possibilita aplicações em modelos conceituais e fenômenos de diferentes naturezas, enfocando a integração nas várias ciências: naturais, sociais, humanas etc.

O pensar holístico é condição essencial para a TGS, pois nada pode ser explicado por meio da ordenação ou disposição das partes, mas sim por meio das relações que elas mantêm entre si e com o todo. Um sistema não vive isolado, é sempre parte de um todo. É geral para as partes que o compõe e é parte da composição de outro sistema mais amplo. Ela pode ser aplicada a diversos tipos de sistemas: físicos, biológicos, psicológicos, organizacionais etc., e a única maneira inteligível de estudar uma organização é estudá-la como um sistema, uma vez que sua análise pressupõe variáveis mutuamente dependentes (BERTALANFFY, 1975).

Segundo Bertalanffy (1975), a partir das problemáticas das Ciências Biológicas, Sociais e Comportamentais, foi possível romper o reducionismo da Física, influindo na busca de conceitos científicos e modelos mais abrangentes. 
Para esse autor, a abordagem sistêmica resultou da insuficiência do esquema mecanicista no tratamento das partes. As principais funções da TGS são: a) investigar a isomorfia dos conceitos, leis e modelos, promovendo a transferência útil de um campo para outro; b) encorajar a criação de modelos teóricos adequados em campos que, ainda, não existem; c) reduzir, ao mínimo, a duplicação do esforço teórico em diferentes campos; d) promover a unidade da ciência, mediante a melhoria da comunicação entre os especialistas.

A TGS busca produzir teorias e formulações conceituais que possam ser aplicadas em uma determinada realidade. Além disso, pode ser compreendida como a teoria mais abrangente para estudar os campos não físicos do conhecimento científico, especialmente, no âmbito das Ciências Sociais.

Segundo Santos, Pelosi e Oliveira (2012), a TGS enfoca o processo e a percepção do todo, suas inter-relações e suas interdependências. Contudo, a principal crítica à TGS está na tentativa de explicar os fatos sociais, a partir de conceitos das Ciências Naturais que pressupõem que o objeto tende a se tornar previsível e controlável, ou seja, o sistema é considerado mais importante que o homem. Portanto, ela não leva em conta o papel da cultura, da intencionalidade, da noção de poder, do conflito e da dominação.

A revolução científica ocorre quando um paradigma é superado e outro torna-se mais apropriado, transformando os princípios organizadores do conhecimento. Portanto, a TGS perde espaço para TC, porquanto não dá conta da complexidade inerente a qualquer tipo de sistema (SANTOS; PELOSI; OLIVEIRA, 2012). Evidencia-se que a TGS também está associada à origem do conceito de interdisciplinaridade.

A TC evolui da TGS e não concebe sistemas fechados, ela desconstrói o equilíbrio, a verdade, a estabilidade e a permanência presentes na TGS e é considerada uma teoria mediadora que compreende um amplo corpo de conhecimentos. Enfoca, especialmente, sistemas dinâmicos não lineares, cujo comportamento imprevisível perpassa disciplinas tradicionais e contraria o mecanicismo clássico; ela traz em seu bojo confusão, incerteza e desordem (MORIN, 2005). Assim, a complexidade é aplicada nas mais variadas áreas do pensamento humano, cujas características atuam de contraponto ao classicismo 
científico, expondo o reducionismo, a fragmentação e a compartimentalização do saber.

Para Morin (2005), o pensamento complexo aspira um saber não fragmentado, não compartimentado e não redutor: o reconhecimento do inacabado e da incompletude de qualquer conhecimento, sendo fundamental compreender que a simplicidade não exclui a complexidade.

No pensamento complexo, a soma das partes ultrapassa o todo. Em uma abordagem compartimentalizada, uma árvore é composta apenas de raiz, caule, folha e fruto, já em uma abordagem complexa e sistêmica, ela também precisa da luz do sol, do ar, da terra etc., ou seja, ao se referir à complexidade, relacionamos ela à ideia de diversas áreas associadas e não fundidas (MORIN, 2005).

O autor supracitado apresenta a complexidade como um tecido de constituintes heterogêneos inseparavelmente associados, ou seja, um paradoxo do uno e do múltiplo. Além disso, ele afirma que a complexidade é efetivamente o tecido de acontecimentos, ações, interações, retroações, determinações, acasos, que se constituem no mundo fenomenal que vivenciamos (MORIN, 2005).

Infere-se, com base em Morin (2005), que a sociedade é multifacetada como um prisma, e a TC ajuda o pesquisador a libertar-se de modelos fragmentados. Nesse sentido, passa-se a trabalhar modelos híbridos, visando à integralização de saberes.

A TC refuta todas as formas de pensamento unilateral, dogmático, reducionista etc., rejeita a ideia de verdades absolutas. Sendo assim, incorpora a incerteza como parte natural de qualquer objeto ou fenômeno, considerando o universo como um todo indissociável e, assim, dá lugar à criatividade e ao caos.

$\mathrm{Na}$ TC ressalta-se a importância da dualidade (ordem/desordem) e da percepção de que o homem faz parte dos processos complexos, interferindo e sendo responsável. Portanto, não é possível colocar-se no papel de mero expectador, uma vez que a complexidade engloba além do objeto: o objeto apreende o sujeito e o sujeito apreende o objeto em constante movimento.

Segundo Morin (2000b), o pensamento complexo é, essencialmente, o 
pensamento que trata da incerteza e é capaz de conceber a organização, ou seja, é capaz de reunir "[...] de contextualizar, de globalizar, mas ao mesmo tempo, capaz de reconhecer o singular, o individual, o concreto" (MORIN, 2000b, p. 207). A partir do pensamento complexo, que trata a incerteza e o concreto, na próxima seção, a especialização e hiperespecialização serão discutidas.

\subsection{Especialização e hiperespecialização: preocupações}

A reflexão sobre as inter-relações, muitas vezes, se depara com um problema, o da especialização e hiperespecialização, que estabelece um verdadeiro mosaico de disciplinas que não se comunicam, o que impossibilita a reflexão entre disciplinas e objetos. Além disso, ocasiona um fenômeno ainda pior que é o da fragmentação, desintegração das realidades (MORIN, 2000a).

A especialização

[...] que extrai um objeto do seu contexto e do seu conjunto, rejeita os laços e as intercomunicações com o seu meio e o insere em um compartimento, que [...] destroem arbitrariamente a sistematicidade $\quad[\ldots]$ e $\quad$ a multidimensionalidade dos fenômenos [...]. (MORIN, 2000b, p. 207).

Segundo o mesmo autor, o conhecimento deve utilizar a abstração para procurar construir contextos, pois a compreensão dos dados gerais pressupõe a ativação da inteligência geral e, dessa forma, é necessário mobilizar o todo. Morin (2000a) não critica a especialização, mas sim a hiperespecialização que impede tanto a percepção do global quanto do essencial, visto que,

[...] os problemas essenciais nunca são parcelados e os problemas globais são cada vez mais essenciais. Enquanto a cultura geral comportava a incitação à busca da contextualização de qualquer informação ou ideia, a cultura científica e técnica disciplinar parcela, desune e compartimenta os saberes, tornando cada vez mais difícil sua contextualização. (MORIN, 2000a, p. 41).

As Ciências Sociais, ao se preocuparem com a especialização e a hiperespecialização, esquecem-se do cerne de seu questionamento: o homem, visto que na especialização os indivíduos restringem-se, cada vez mais, ao desinteresse e ignorância relacionada ao todo. É fundamental a distinção entre 
os conhecimentos, mas não a dissociação dos mesmos, uma vez que a subjetividade e a objetividade devem conviver, pois, a Ciência não está na certeza, ela é mutável e pode ser refutada.

A informação pode informar ou desinformar, esclarecer ou confundir. Quando se analisa a especialização e a hiperespecialização, apresenta-se a impossibilidade de generalizar, dado que tudo depende do contexto. A Ciência progride por meio da separação dos problemas e de sua divisão em disciplinas, cujos objetos são delimitados. Entretanto, isto conduz àquilo que Morin (2004) denomina de hiperespecialização, já que as ciências deixam de se comunicar entre si.

O pensamento complexo emerge das fissuras do pensamento simplificador ainda dominante, porém, é desse aparente paradoxo da ciência simplificadora que a complexidade surge, e a ciência simplificadora é compreendida como complexa. Por oposição ao conceito determinista de causalidade, é preciso pensar sobre a recursividade, ou seja, a possibilidade de a causa agir sobre o efeito, e do efeito agir sobre a causa (MORIN, 2004).

Segundo Japiassu (2006) e Fazenda (2007), a especialização nascida no século XIX e a aceleração dos conhecimentos e das sofisticações das tecnologias influíram, significativamente, no surgimento da hiperespecialização na metade do século XX, provocada pela multiplicação indefinida de disciplinas e subdisciplinas, cada vez mais focadas na redução dos objetos de estudo. Segundo os autores supracitados, é, nesse momento, que as disciplinas tornamse fechadas, estanques, fontes de glória, ciúmes, poder, arrogâncias e atitudes dogmáticas.

Vale ressaltar que não se pretende negar a importância da especialização, mas sim evidenciar a necessidade de uma visão complexa, que desenvolva pensamentos que estabeleçam interações e estejam aptos a perceber diferenciações, uma vez que o

[...] processo é circular, passando da separação à ligação, da ligação à separação, e, além disso, da análise à síntese, da síntese à análise. [...] o conhecimento comporta, ao mesmo tempo, separação e ligação, análise e síntese. (MORIN, 2002, p. 24). 
Nesse sentido, Morin (2002) complementa sua ideia criticando o modelo de educação ou o sistema educacional contemporâneo que privilegia a separação em detrimento da ligação e a análise em detrimento da síntese, visto que, segundo ele, ligação e síntese continuam subdesenvolvidas.

Evidencia-se, assim, a importância de se entender e discutir a interdisciplinaridade como um diferencial, uma vez que ela pressupõe troca, cooperação e organização, ou seja, um movimento integrador de saberes.

\section{Interdisciplinaridade}

Observa-se que as ciências, na busca do aperfeiçoamento do conhecimento humano, desenvolvem-se ao evidenciar lacunas ou vulnerabilidades em suas configurações e teorias, isto é, os paradigmas vigentes. A especialização e a hiperespecialização que geram a dissociação dos conhecimentos, motivam o surgimento da interdisciplinaridade como uma alternativa que busca uma visão conjunta, gerando a interação entre diversas disciplinas. Constatam-se ações, em

algumas áreas do conhecimento, que se empenham em praticar a interdisciplinaridade, uma vez que, invariavelmente, não é possível encontrar todas as respostas a partir de uma visão singular.

Visando uma melhor compreensão em relação à interdisciplinaridade, no intuito de propor um conceito mais amplo, são discutidas algumas definições sobre esta temática. Muitas são as possibilidades de leitura para discutir a interdisciplinaridade, no entanto, para esse artigo foi dada atenção especial a Japiassu (1976), Pombo (2004) e Fazenda (2011), visto que os referidos autores são referência sobre esses estudos.

\subsection{Interdisciplinaridade: definições e observações}

O indivíduo, ao identificar o inacabado, pode desenvolver o desejo de obter respostas mais satisfatórias ou adequadas aos seus anseios. Japiassu (1976, p. 24) destaca que "[...] o remédio à desintegração do saber consiste em trazer, à dinâmica da especialização, uma dinâmica compensadora de não-especialização 
[...]", ou seja, para minimizar a disjunção entre as áreas, é necessário adotar condutas que possibilitem o estabelecimento de correlação entre elas.

A interdisciplinaridade é resultante da adoção de ações que visam aproximar os saberes e as práticas. Assim, considerando a necessidade de uma maior interação entre distintos conhecimentos, a interdisciplinaridade surge tanto para diluir as fronteiras entre disciplinas, quanto para explorar a transversalidade entre os diferentes conhecimentos (POMBO, 2004).

Esta abordagem busca a integração de distintas disciplinas, subsidiando novas maneiras de se investigar os fenômenos deste mundo. Japiassu (1976) e Fazenda (2011) destacam como característica principal da interdisciplinaridade, a intensidade que deve haver nas trocas entre os especialistas, visando a real integração das disciplinas envolvidas. Para Pombo (2004, p. 29), a interdisciplinaridade promove o diálogo entre as disciplinas e decorre da fragilidade das diferentes ciências, visto que é nela em que, atualmente, "[...] se reconhecem as nossas reflexões sobre a condição fragmentada das ciências."

Evidencia-se que o exercício interdisciplinar, no contexto científico, visa suplantar a adoção de práticas desagregadoras. Pombo (2004) destaca como malefícios consequentes da adoção da Ciência Moderna, o desconhecimento e o desinteresse sobre assuntos de outras áreas; a estrutura institucional do trabalho científico, dividida internamente em inúmeras comunidades, preocupadas apenas com interesses próprios; e a patentificação das áreas de investigação ou de uma área de pensamento.

A interdisciplinaridade afasta-se da ideia unificada e da subdivisão de saberes, busca uma exploração mais totalitária dos fenômenos desse mundo. Pombo (2004) destaca que ocorrem os programas mais significativos sobre a interdisciplinaridade na TGS, e o que mais importa a esta teoria é entender a inter-relação entre as várias ciências, considerando os possíveis cruzamentos e transferências entre elas. 


\subsection{A prática da interdisciplinaridade: uma ação difícil?}

A adoção da interdisciplinaridade instiga o aprofundamento para a construção de conhecimento, em vista de sua característica integradora, uma vez que é necessário desenvolver práticas que promovam o entendimento mútuo entre os saberes das áreas envolvidas.

O exercício da interdisciplinaridade - considerando a necessidade de comunicação entre as disciplinas e o emprego de novas práticas de construção de conhecimento - propicia novas maneiras de se fazer ciência, pois:

[...] sob o programa da interdisciplinaridade, é possível referenciar dois grandes fenômenos: a funcionalização da prática científica e a unificação do conhecimento pela performatividade. (POMBO, 2004, p. 153).

É o aprimoramento do saber idealizado pela prática interdisciplinar que torna a integração mais evidente na elaboração de um conhecimento único.

No entanto, é possível que surjam sentimentos relacionados à insegurança, à arrogância e ao egoísmo entre os pesquisadores envolvidos, visto que uma pesquisa interdisciplinar deve propiciar a entrada de pesquisadores de outras áreas e vice-versa. Nesse processo, Pombo (2004, p. 160) ressalta que "Os participantes não abdicam dos seus privilégios territoriais, das suas fronteiras disciplinares no interior das quais se sentem seguros de uma qualquer competência científica.”

A prática interdisciplinar necessita ser cuidadosa em função do que o conforto territorial pode causar. Fazenda (2011, p. 17) argumenta que "Infelizmente, por desconhecimento de alguns, essa prática, embora fecunda, ainda é vista como difícil.” Japiassu (1976) destaca a existência de especialistas que dominam cada vez mais os objetos e fenômenos de suas áreas, mas, por outro lado, têm o domínio de outras disciplinas cada vez mais restrito. O desconhecimento pode ser um dos pontos que tornam a aplicação da interdisciplinaridade mais difícil, proporcionando mais especialização ou hiperespecialização.

Em função do desconhecimento, da insegurança e do individualismo existentes nas áreas, “[...] alterar violentamente o curso dos fatos não é próprio 
de uma educação que abraça a interdisciplinaridade.” (FAZENDA, 2011, p. 28). A aplicação da interdisciplinaridade, no âmbito científico, é algo difícil de ser implantado, pois não pode ser abrupta, autoritária, mas sim cuidadosa, para que haja um aproveitamento de conhecimentos e não sua suplantação. Um trabalho interdisciplinar - para o qual não estamos preparados - desperta a vontade de aprender e de intervir, sem destruir o construído (FAZENDA, 2011).

A aplicação da interdisciplinaridade depara-se com as barreiras anteriormente mencionadas, tornando seu caminho árduo. No entanto, seu exercício é essencial, já que o pesquisador não pode mais se contentar com o ofuscamento da realidade, em função do egocentrismo e da insegurança existentes nas diversas áreas do conhecimento. É preciso haver uma maior compreensão da exploração interdisciplinar, no contexto científico, e das vantagens que ela pode propiciar.

\subsection{Proposta embrionária do conceito de interdisciplinaridade}

Conceituar 'interdisciplinaridade' apresenta-se como uma atividade tão árdua quanto à sua aplicabilidade. Assim, na tentativa de se compilar um conceito embrionário para a interdisciplinaridade, destacam-se algumas abordagens e conceituações extraídas a partir de leituras e reflexões. Pode-se inferir que a interdisciplinaridade:

a) reconhece a condição fragmentada da Ciência;

b) funcionaliza a prática científica;

c) evidencia os problemas metodológicos da Ciência Moderna;

d) entende a inter-relação entre as disciplinas e os possíveis cruzamentos e transferências;

e) pressupõe diálogo aberto entre disciplinas e pesquisadores;

f) coloca o homem como objeto das ciências, pois gera intersubjetividade;

g) apresenta cautela, cuidado e dificuldade na construção de 'novo' conhecimento;

h) interfere na construção de 'novo' conhecimento, sem destruir o anteriormente construído; 
i) necessita da interação entre duas ou mais disciplinas;

j) intensifica as trocas teóricas e metodológicas entre especialistas para gerar 'novo' conhecimento;

k) conta com pesquisadores que nem sempre abdicam de seus privilégios territoriais.

A partir das considerações supracitadas, compilou-se um conceito embrionário de interdisciplinaridade: Interdisciplinaridade é uma ação de exploração científica que promove a inter-relação de conhecimentos e metodologias oriundos de duas ou mais disciplinas, objetivando construir 'novo' conhecimento que responda aos anseios científicos das áreas envolvidas.

\section{Características da Ciência da Informação}

É recorrente, nas publicações da área de CI, apresentá-la como uma Ciência Pós-Moderna e interdisciplinar. Uma defesa muito utilizada é a de que a CI foi constituída a partir de diferentes ciências ou áreas afins, entre as mais citadas estão a Informática, a Biblioteconomia e a Documentação. No entanto, acreditase que, para que um campo científico possa ser considerado uma ciência pósmoderna, as considerações devem recair sobre a maneira como lida com seus objetos e fenômenos, e, o mais importante, como inter-relaciona esses saberes com outras áreas.

Wersig (1993) não considera a CI uma Ciência Clássica, mas sim um protótipo de um novo tipo de Ciência, considerando-a uma Ciência PósModerna, voltada para estudos de novos problemas da sociedade. Araújo et al. (2007) destacam características que, dissociadas do contexto da modernidade, têm sido apresentadas como evidências de uma pós-modernidade, tais como a perda de confiança na razão, as metanarrativas do conhecimento científico tradicional, a interdisciplinaridade, a virtualização das relações humanas, a preocupação com os problemas ambientais, o consumismo, entre outros aspectos. Outros autores, como Boaventura Santos, Edgar Morin e Fritjof Capra têm postulado a existência de uma nova maneira de fazer Ciência, ou o 
surgimento de um novo tipo de Ciência, denominada de Pós-Moderna (ARAÚJO et al., 2007).

Em relação a sua caracterização como Ciência Social, visto que o 'social' é marcante no pós-modernismo, além de situar o sujeito no centro das pesquisas, percebe-se o sujeito reflexivo; ele é o cerne, o foco, a parte do todo que se relaciona com o ambiente e com o contexto. A CI não surge como uma Ciência Social, mas identifica-se, ao longo do tempo, com o escopo das Ciências Sociais Aplicadas, na medida em que se orienta para uma aplicação, em que o sujeito é visto como o principal ator e objetivo dos chamados sistemas de informação (ARAÚJO et al., 2007).

Le Coadic (1996) compreende a CI como uma Ciência Social, uma vez que está preocupada em esclarecer problemas sociais relacionados à informação, e, ao se voltar para o ser social, que procura a informação, situa-se no campo das Ciências Sociais (ciências do homem e da sociedade), que são o principal meio de acesso a uma compreensão do social e do cultural. É, também, considerada interdisciplinar, por haver uma colaboração entre distintas disciplinas, cujas interações propiciam a reciprocidade de trocas, para o enriquecimento mútuo entre pesquisadores e áreas de estudo (LE COADIC, 1996).

Vale ressaltar que não há consenso na literatura da área de CI, no que tange a ela ser uma Ciência Pós-Moderna, social e interdisciplinar. Em uma pesquisa envolvendo professores e pesquisadores brasileiros da CI, Araújo et al. (2007) identificaram justificativas diversas que foram mencionadas pelos sujeitos pesquisados, em torno de três distintas características:

a) Pós-Moderna - porque apresenta características pós-modernas; nasceu no momento histórico da pós-modernidade; atende às novas demandas e estabelece um paradoxo entre o objeto antigo e as ferramentas pósmodernas.

b) social - porque apresenta aplicação social; utiliza métodos, teorias e processos das Ciências Sociais; tem objeto social; é, eminentemente, humana e social; e é um sistema social.

c) interdisciplinar - porque tem relações com diferentes áreas do conhecimento; tem outras áreas que precisam da CI; é fronteira entre a 
inter e a transdisciplinaridade; e apresenta características das ciências contemporâneas.

Desse modo, a seguir apresenta-se um panorama da CI como Ciência interdisciplinar, a partir de sua relação e envolvimento com outras áreas e disciplinas. Para isso, utiliza-se como fundamento os estudos que demonstram essa relação interdisciplinar.

\section{Interdisciplinaridade no âmbito da Ciência da Informação}

Segundo Pinheiro (1998), a CI tem um objeto de estudo de difícil apreensão. A CI:

[...] tem seu próprio estatuto científico, como Ciência Social que é, portanto, interdisciplinar por natureza, e apresenta interfaces com a Biblioteconomia, Ciência da Computação, Ciência Cognitiva, Sociologia da Ciência e Comunicação [...]. (PINHEIRO, 1998, p. 155).

Apresenta-se no Quadro 1, a percepção de diferentes pesquisadores sobre a relação interdisciplinar da CI com outras áreas do conhecimento, a partir de estudo realizado por Pinheiro (2008).

Quadro 1 - Relações interdisciplinares com a Ciência da Informação.

\begin{tabular}{|c|c|c|}
\hline Pesquisador & Ano & Disciplinas \\
\hline Borko & 1968 & $\begin{array}{l}\text { Administração } \\
\text { Artes Gráficas } \\
\text { Biblioteconomia } \\
\text { Computação } \\
\text { Comunicação } \\
\text { Linguística } \\
\text { Lógica } \\
\text { Matemática } \\
\text { Pesquisa de operações } \\
\text { Psicologia }\end{array}$ \\
\hline Mikhailov, Chernyi, Gilyarevskyi & 1969 & $\begin{array}{l}\text { Biblioteconomia } \\
\text { Psicologia } \\
\text { Semiótica }\end{array}$ \\
\hline Kitagawa & 1971 & Estatística \\
\hline Fosket & 1980 & $\begin{array}{l}\text { Biblioteconomia } \\
\text { Computação } \\
\text { Comunicação } \\
\text { Linguística } \\
\text { Psicologia }\end{array}$ \\
\hline Machlup e Mansfield & 1983 & $\begin{array}{l}\text { Biblioteconomia } \\
\text { Cibernética } \\
\text { Ciência Cognitiva } \\
\text { Ciências Sociais } \\
\text { Computação }\end{array}$ \\
\hline
\end{tabular}




\begin{tabular}{|l|l|l|}
\hline & & Inteligência Artificial \\
& Linguística \\
& Teoria da Informação \\
& Teoria do Conhecimento \\
& Teoria dos Sistemas \\
\hline \multirow{3}{*}{ Saracevic } & Biblioteconomia \\
& Ciência Cognitiva \\
& Ciência da Computação \\
& Comunicação \\
& Inteligência Artificial \\
& Tecnologias da Informação \\
\hline
\end{tabular}

Fonte: Adaptado de Pinheiro (2008).

Observa-se que as relações interdisciplinares indicadas pelos pesquisadores supracitados no Quadro 1 são diferentes. Entretanto, é importante levar em conta o período e o contexto em que essas relações foram realizadas. Segundo o estudo, evidencia-se a percepção da interdisciplinaridade especialmente entre a CI, a Biblioteconomia e a Computação.

Existem aspectos que interferem no território interdisciplinar da área, como a origem, a natureza, o objeto de estudo, a informação e as disciplinas que a constituem (PINHEIRO, 1998). É do conjunto de disciplinas que compõe a CI que pode ser pensada a interdisciplinaridade, isto é, de que maneira os outros campos contribuem para ela e vice-versa.

Saracevic (1999 ${ }^{1}$ apud PINHEIRO, 2006) apresenta duas justificativas para a interdisciplinaridade da CI. A primeira é que seus problemas não podem ser resolvidos por abordagens ou construtos de uma única disciplina. A segunda, por sua vez, é que a interdisciplinaridade foi introduzida na área e continua sendo até hoje, pelas muitas diferenças de formação [background] e áreas de origem das pessoas que tratam dos problemas da CI. Saracevic reconhece a fragilidade e o inacabamento da CI, e que ela, portanto, necessita de outras disciplinas para resolver seus problemas e questionamentos.

[...] percebemos que o campo interdisciplinar da Ciência da Informação vai se movendo e gradativamente adquirindo novas configurações, pela circularidade e como numa espiral, na concepção de Morin. Disciplinas e subáreas do campo e seus problemas, que exigem soluções de outras áreas, promovem transformações interdisciplinares e, inversamente, estas novas relações epistemológicas vão modificando o território da área. (PINHEIRO, 2006, p. 27). 
A autora destaca o pensamento de Morin para ilustrar que a CI vai se constituindo em uma espiral, ganhando forma e corpo conforme se relaciona com outras áreas do conhecimento. Sendo assim, o pensamento complexo está intimamente relacionado a essa construção gradativa e espiralada.

\subsection{Estudos que demonstram as possíveis relações interdisciplinares da CI}

Escolheu-se analisar os estudos realizados por Pinheiro e Loureiro (1995) e Pinheiro (2006), por sua amplitude e por apresentarem a relação interdisciplinar da CI com outras áreas do conhecimento. O estudo realizado por Pinheiro e Loureiro, em 1995, apresenta o cenário interdisciplinar que a CI tinha constituído, a partir de 12 subáreas e 49 disciplinas (Figura 1).

Figura 1 - Interdisciplinaridade da Ciência da Informação - 1998.

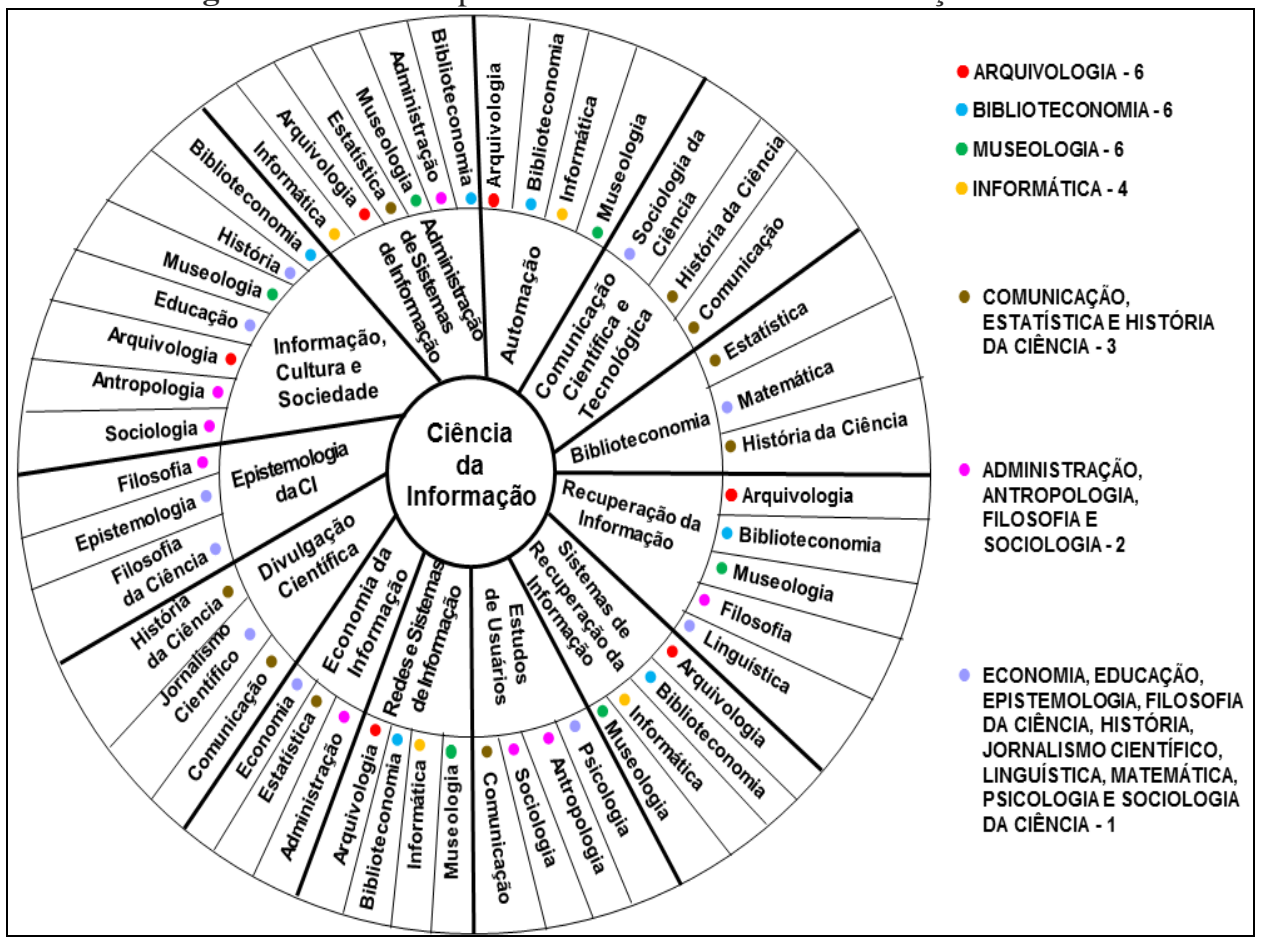

Fonte: Adaptado de Pinheiro e Loureiro (1995 apud PINHEIRO, 1998).

Após o estudo realizado em 1995, Pinheiro o atualizou em 2006 (Figura 2). Assim, é possível observar a mudança em relação ao cenário interdisciplinar inicial. 
Figura 2 - Interdisciplinaridade da Ciência da Informação - 2006.

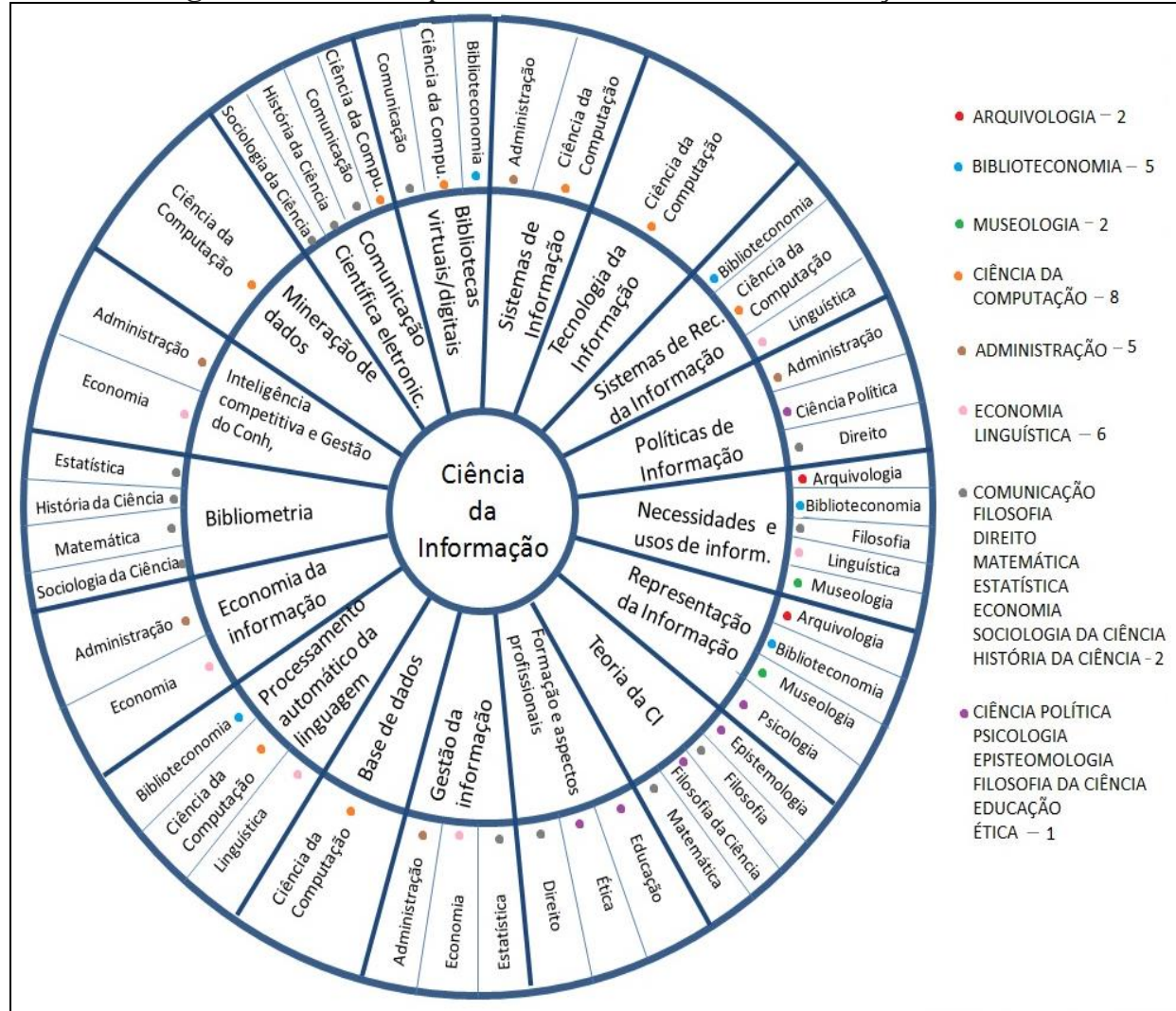

Fonte: Adaptado de Pinheiro (2006).

Neste esquema, é possível visualizar 17 subáreas e 48 disciplinas. De um estudo para o outro, revela-se a mudança em relação à permanência, o surgimento e o desaparecimento de algumas áreas e disciplinas mencionadas nos estudos. Algumas disciplinas como a Arquivologia e a Museologia tiveram uma ocorrência menor no segundo estudo. Por outro lado, disciplinas como Administração, Computação, Economia e Linguística tiveram a ocorrência elevada em relação ao primeiro estudo.

Em outra pesquisa mais recente, realizada por Bicalho e Oliveira (2011), é possível observar que o nível de interação entre a CI e outras disciplinas ocorre, mais efetivamente, por meio da multidisciplinaridade do que pela interdisciplinaridade. Acredita-se que esse resultado seja pelo fato de que a multidisciplinaridade não exige o mesmo grau de aprofundamento e integração entre os saberes envolvidos, como na interdisciplinaridade.

Observa-se que os estudos que buscam identificar a característica interdisciplinar da CI estão relacionados a estudos bibliográficos e 
bibliométricos, como, por exemplo, a pesquisa de Moraes e Carelli (2016) que buscou identificar e analisar as citações e as referências de outras áreas e disciplinas, visando à discussão da problemática apresentada no âmbito da CI. Mas se a interdisciplinaridade exige que haja cooperação mútua entre as áreas e apropriação de saberes construídos conjuntamente, é necessário um outro olhar sobre esses estudos, ou seja, é necessário verificar como se dá a ocorrência de citação de autores da CI nas áreas recorrentemente citadas no âmbito da CI, como a Administração, a Computação etc. Visto que a interdisciplinaridade se caracteriza pela "[...] intensidade das trocas realizadas entre os cientistas especializados e o grau de integração real das disciplinas [...]" (BICALHO; OLIVEIRA, 2011), assim, é fundamental verificar essa integração nas demais disciplinas que contribuem para o corpus da CI, e não somente no contexto dela própria. A análise deve ser realizada além das fronteiras da CI, no intuito de descobrir quais disciplinas têm incorporado conhecimento dessa área à sua de origem.

Figura 3 - Relação interdisciplinar da Ciência da Informação com outras áreas.

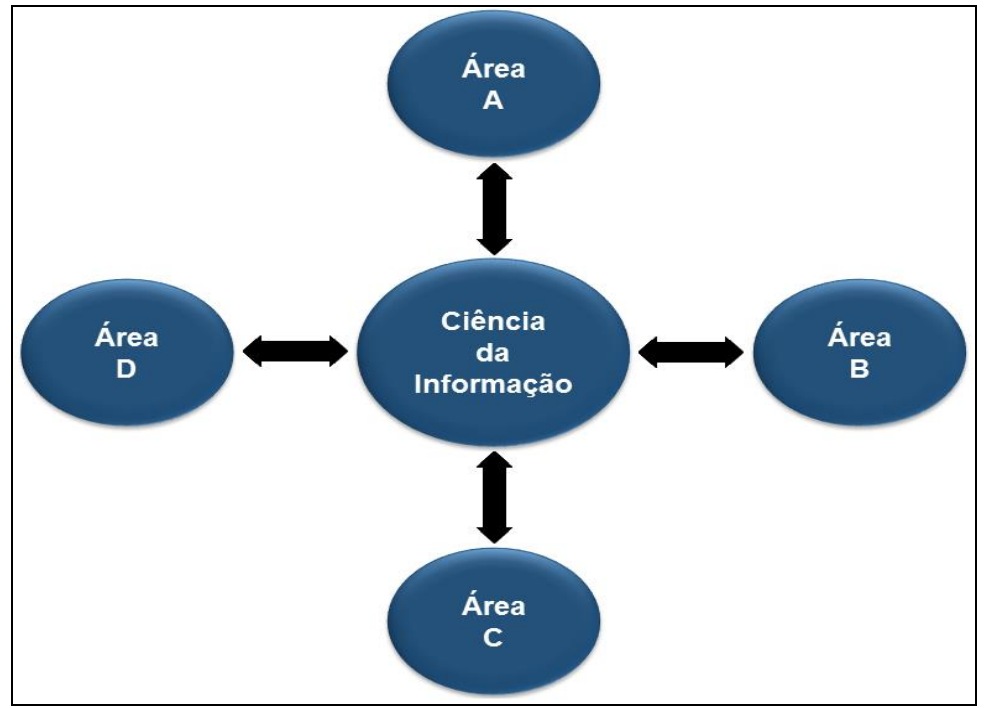

Fonte: Elaborado pelos autores.

A Figura 1 representa uma efetiva interação interdisciplinar, na qual as setas indicam reciprocidade, demonstrando a troca mútua entre as disciplinas e seus saberes. Os estudos, em sua maioria, visam descobrir quais são as áreas que 
a CI tem se apropriado, mantendo de fato uma relação interdisciplinar (MORAES; CARELLI, 2016; PINHEIRO, 1998, 2006, 2008; FREIRE; SILVA, 2012; SANTANA, 2012). Seria necessário verificar como a CI tem contribuído para as outras áreas de conhecimento, ou seja, quais são os fundamentos, conceitos, métodos, processos ou produtos originados dessa área, que foram incorporados nas áreas $\mathrm{A}, \mathrm{B}, \mathrm{C}$ ou $\mathrm{D}$ (por exemplo), denotando uma real contribuição.

Acredita-se, a partir dessa perspectiva, que será possível verificar como a CI apropria-se de outras áreas e vice-versa, e, também, constatar a efetividade estabelecida na relação interdisciplinar entre as áreas.

Contudo, Smith (1992² apud PINHEIRO, 2006) observa que é necessário haver espaços específicos para discussão e reflexão sobre determinados temas que circundam a área, mas é importante que haja a consciência de que as fronteiras entre essas temáticas são frágeis e necessitam do diálogo com outras. O perigo está na especialização ou hiperespecialização tornar cegos e inconscientes os membros que frequentam esses espaços, que deveriam ser de troca e socialização de conhecimento.

\section{Considerações finais}

Por se tratar de uma ciência relativamente nova e complexa que ainda busca seu espaço e reconhecimento junto às demais áreas e disciplinas, é possível inferir que a CI mais consome conhecimento de outras áreas, do que propriamente é consumida. Infere-se que uma hipótese para que isso ocorra, relaciona-se ao fato de que, apesar de a CI ter muito a oferecer, falta percepção por parte das outras áreas, em relação às importantes contribuições que a CI poderia aportar aos estudos realizados e aos possíveis usos.

Nessa perspectiva, vale diferenciar 'interdisciplinaridade' de 'aplicação', pois, utilizar métodos e procedimentos científicos de outras áreas e disciplinas não assegura o fato de se realizar um trabalho interdisciplinar. A partir das leituras realizadas, defende-se que a CI, a Biblioteconomia e a Ciência da Computação exercem um diálogo interdisciplinar, isto é, essas áreas realmente 
interagem e criam conhecimento, ou aperfeiçoam o já existente, sendo útil e reconhecido por todas as áreas envolvidas. Esta constatação fundamenta-se na pesquisa de Lena Vania Pinheiro e, também, na pesquisa mais recente de Moraes e Carelli (2016), ao afirmarem que o caráter interdisciplinar da CI se dá com a Administração, a Ciência da Computação, a Educação e a Sociologia.

Defende-se que a efetiva construção de conhecimento só ocorre nessa dialogia, entre ordem e desordem, entre construção e desconstrução. Sem isso não é possível analisar, sintetizar e refletir. O pensamento complexo reúne e globaliza, mas, ao mesmo tempo, separa e reconhece o individual.

$\mathrm{Na}$ interdisciplinaridade, as fraquezas e os limites são reconhecidos, além da unidade dos saberes, ou seja, trabalhar a interdisciplinaridade é reconhecer o inacabamento dos objetos e fenômenos estudados, ter a humildade para assumi-lo ao outro e, portanto, demonstrar que necessita do outro. $\mathrm{Na}$ interdisciplinaridade, apropria-se e socializa-se ao mesmo tempo, é uma via de mão dupla, caso contrário seria uma pluri ou multidisciplinaridade.

A interdisciplinaridade pressupõe o aprofundamento, não se pode ficar na superficialidade. E, como abordado anteriormente, é importante que o conhecimento gerado na interdisciplinaridade seja reconhecido por todas as partes envolvidas, e que essa construção de caráter inovador ou incorporador, seja legítima. Se, naturalmente, esse conhecimento é reconhecido, ele passa a ser aceito e 'reproduzido' e, no futuro, poderá ser aplicado em uma dada realidade.

Como proposto, a interdisciplinaridade dá espaço para a dinâmica da discussão, requer diálogos, é uma ação de exploração científica que promove a inter-relação de conhecimentos e metodologias oriundos de duas ou mais disciplinas, objetivando construir 'novo' conhecimento que responda aos anseios científicos das áreas envolvidas. No entanto, o que se observa são fronteiras, cada vez mais rígidas, cuja abertura ao novo e ao desconhecido é problemática.

Como construir conhecimento novo ou que incorpore o já existente, a partir de relações científicas interdisciplinares? A partir de uma visão ecológica e ecofísica que reconhece a complexidade das coisas. E isso ocorre, em um longo processo, que tem um tempo de maturação necessário, que vai interferir 
no andamento das disciplinas que participam do referido processo. Portanto, conhecer e compreender a Teoria da Complexidade é condição sine qua non para a realização de estudos interdisciplinares.

\section{Referências}

ARAÚJO, C. A. Á. et al. A Ciência da Informação na visão dos professores e pesquisadores brasileiros. Informação \& Sociedade: estudos, João Pessoa, v. 17, n. 2, p. 95-108, maio/ago. 2007. Disponível em:

〈http://www.ies.ufpb.br/ojs/index.php/ies/article/view/637>. Acesso em: 3 nov. 2015.

BAUDRILLARD, J. Simulacros e simulação. Lisboa: Relógio D’Água, 1991.

BERTALANFFY, L. Teoria geral dos sistemas. Petrópolis: Vozes, 1975.

BICALHO, L.; OLIVEIRA, M. Aspectos conceituais da transdisciplinaridade e a pesquisa em Ciência da Informação. Informação \& Sociedade: Estudos, João Pessoa, v. 21, n. 2, p. 87-102, maio/ago. 2011. Disponível em:

<http://www.ies.ufpb.br/ojs/index.php/ies/article/view/9746/5964>. Acesso em: 03 jul. 2016.

CASTELLS, M. A sociedade em rede. São Paulo: Paz e Terra, 1999.

CHALMERS, A. F. O que é ciência afinal? São Paulo: Brasiliense, 1993.

FAZENDA, I. C. A. Interdisciplinaridade: história, teoria e pesquisa. 14. ed. Campinas: Papirus, 2007.

FAZENDA, I. C. A. Integração e interdisciplinaridade no ensino brasileiro: efetividade ou ideologia. 6. ed. São Paulo: Loyola, 2011.

FREIRE, G. H. A.; SILVA, J. L. C. A configuração do campo da Ciência da Informação: marcas de uma identidade. Informação \& Sociedade: estudos, João Pessoa, v. 22, n. esp., p. 161-174, 2012. Disponível em:

<http://www.ies.ufpb.br/ojs/index.php/ies/article/view/13775/8216>. Acesso em: 02 jul. 2016.

HARVEY, D. Condição pós-moderna. São Paulo: Loyola, 2000.

HENRY, J. A revolução científica e as origens da ciência moderna. Rio de Janeiro: Zahar, 1998.

JAPIASSU, H. O sonho transdisciplinar e as razões da Filosofia. Rio de Janeiro: Imago, 2006. 
JAPIASSU, H. Interdisciplinaridade e patologia do saber. Rio de Janeiro: Imago, 1976.

LE COADIC, Y. F. A Ciência da Informação. Brasília: Briquet de Lemos, 1996.

LEMOS, A. Cibercultura, tecnologia e vida social na cultura contemporânea. Porto Alegre: Sulina, 2002.

LENZI, L. A. F.; BRAMBILA, E. Z. Ciência da informação, ciência e revolução científica: breve histórico e reflexões. Informação \& Informação, Londrina, v. 11, n. 1, jan./jun. 2006. Disponível em:

<http://www.uel.br/revistas/uel/index.php/informacao/article/view/1679/0>.

Acesso em: 29 nov. 2015.

LYOTARD, J.-F. A condição pós-moderna. 8. ed. São Paulo: José Olympio, 2004.

MORAES, M.; CARELLI, A. E. A interdisciplinaridade na Ciência da Informação pela perspectiva da análise de citações. Em Questão, Porto Alegre, v. 22, n. 1, p. 137-160, jan./abr. 2016. Disponível em:

<http://seer.ufrgs.br/index.php/EmQuestao/article/view/56296/36967>. Acesso em: 02 jul. 2016.

MORIN, E. A cabeça bem-feita: repensar a reforma, repensar o pensamento. 6. ed. Rio de Janeiro: Bertrand Brasil, 2002.

MORIN, E. Ciência e consciência da complexidade. In: MORIN, E.; MOIGNE, J. L. A inteligência da complexidade. 3. ed. São Paulo: Peirópolis, 2000a. p. 23-41.

MORIN, E. Introdução ao pensamento complexo. Porto Alegre: Sulina, 2005. 120 p.

MORIN, E. O pensamento complexo, um pensamento que pensa. In: MORIN, E.; MOIGNE, J. L. A inteligência da complexidade. 3. ed. São Paulo:

Peirópolis, 2000b. p. 197-213.

MORIN, E. A religação dos saberes: o desafio do Século XXI. 4. ed. Rio de Janeiro: Bertrand Brasil, 2004.

PINHEIRO, L. V. Campo interdisciplinar da Ciência da Informação: fronteiras remotas e recentes. Investigación Bibliotecnológica, Ciudad de México, v. 12, n. 25, p. 132-163, 1998. Disponível em:

<http://www.revistas.unam.mx/index.php/ibi/article/view/3884/3436>. Acesso em: 31 ago. 2016. 
PINHEIRO, L. V. Ciência da Informação: desdobramentos disciplinares interdisciplinaridade e transdisciplinaridade. In: GONZALEZ DE GOMEZ, M. N.; ORRICO, E. G. D. (Org.). Políticas de memória e informação: reflexos na organização do conhecimento. Natal: EDUFRN, 2006. p. 111-141.

PINHEIRO, L. V. Itinerários epistemológicos da instituição e constituição da informação em arte no campo interdisciplinar da Museologia e da Ciência da Informação. Museologia e Patrimônio, Rio de Janeiro, v. 1, n. 1, p. 9-17, 2008. Disponível em:

$<$ http://revistamuseologiaepatrimonio.mast.br/index.php/ppgpmus/article/view/3 /17>. Acesso em: 06 nov. 2015.

PINHEIRO, L. V.; LOUREIRO, J. M. M. Traçados e limites da Ciência da Informação. Ciência da Informação, Brasília, v. 24, n. 1, p. 42-53, jan./jul.1995.

POMBO, O. Interdisciplinaridade: ambições e limites. Lisboa: Relógio D’Água, 2004.

SANTANA, G. H. C. A Ciência da Informação e sua consolidação em face da interdisciplinaridade. Encontros Bibli, Florianópolis, v. 17, n. 35, p. 1-26, set./dez., 2012. Disponível em:

$<$ http://www.redalyc.org/articulo.oa? id=14724821002>. Acesso em: 29 nov. 2015.

SANTOS, B. de S. Introdução a uma ciência pós-moderna. Rio de Janeiro: Graal, 2003.

SANTOS, L. M. L.; PELOSI, E. M.; OLIVEIRA, B. C. S. C. M. Teoria da Complexidade e as múltiplas abordagens para compreender a realidade social. Serviço Social em Revista, Londrina, v. 14, n. 2, p. 47-72, jan./jun. 2012. Disponível em:

<http://www.uel.br/revistas/uel/index.php/ssrevista/article/view/11823/11637>. Acesso em: 5 nov. 2015.

WERSIG, G. Information Science: The study of postmodern knowledge usage. Information Processing \& Management, New York, v. 29, n. 2, p. 229-239, Mar. 1993. Disponível em: <http://www.sciencedirect.com/science/article/pii/030645739390006Y>. Acesso em: 21 nov. 2015.

\section{Interdisciplinarity in the context of Information Science: currents and questions}

Abstract: This article investigates interdisciplinarity in the context of Information Science (CI), its concepts and characteristics from a literature 
review. It aims to elucidate the discussion of the theme and the approaches that have been used in studies; it also proposes an embryonic concept for interdisciplinarity. It analyzes the first studies by Lena Vania Pinheiro and confronts them with the latest researches. The study concludes that the CI, Library science and Computer science perform an interdisciplinary dialogue, that is, these areas interact and create knowledge or improve the existing, being useful and recognized by all the involved areas.

Keywords: Interdisciplinarity. Information Science. Complexity Theory.

Recebido: 03/03/2016

Aceito: $28 / 07 / 2016$

SARACEVIC, T. Information Science. Journal of The American Society for Information Science, v,50, n.12, p.1051-1063, 1999.

2 SMITH, L. Interdisciplinarity: approaches to understanding library and information Science as an interdisciplinary field.In: VAKKARI, Pertti, CRONIN, Blaise , ed. Conceptions of Library and Information Science: historical, empirical and theoretical perspectives. Proceedings of the International Conference held for the celebration of 20th Anniversary of the Department of Information Studies. University of Tampere, Finland, 26-28, August 1991. London, Los Angeles: Taylor Graham,1992. p.253267. 